International Journal of Engineering \&Technology, 7(4.24) (2018) $71-75$
International Journal of Engineering \& Technology
SPC
Website: www.sciencepubco.com/index.php/IJET
Research paper

\title{
Torque Ripple Reduction in Brushless DC Motor by Using SPWM and SVPWM Techniques
}

\author{
Ch.N. NarasimhaRao ${ }^{1}$, G. Durga Sukumar ${ }^{2}$, R. Vinod Kumar ${ }^{3}$ \\ ${ }^{1}$ V.F.S.T.R (Deemed to be University) \\ ${ }^{2}$ V.F.S.T.R Deemed to be University) \\ ${ }^{3}$ V.F.S.T.R (Deemed to be University) \\ * Corresponding author E-mail: E-mail:narsi.cherukuri@gmail.com
}

\begin{abstract}
Brushless DC motors have the large applications because of its easiest control system and the highest efficiency. Industrial BLDC motor drives suffers from the ripples in the torque, due to which motor has more noise, vibrations and less efficient. To reduce the ripple, the Space Vector PWM (SVPWM) and Sinusoidal PWM are implemented in BLDC drive. The Pulse Width Modulation (PWM) controls the converter output voltage and frequency. Space Vector PWM (SVPWM)and Sinusoidal PWM are the best techniques used in industries because its easy design. Space Vector PWM control method is implemented and it overcomes the disadvantages in PWM such as losses in switching of the converter, output harmonic content\& provides better DC-bus voltages. The torque ripples are also reduced in SVPWM method compared to SPWM method. In this paper BLDC motor with a fuzzy controller is presented and the comparison in performance of SVPWM \&SPWM methods presented. The SVPWM makes the drive has less ripple in torque\& noiseless operation. The Matlab/Simulink models of SVPWM and SPWM method with fuzzy controlled BLDC motor also presented.
\end{abstract}

Keywords: BLDC Motor, SPWM, SVPWM, FUZZY, Matlab/Simulink.

\section{Introduction:}

Brushless DC motor (BLDC) rotor has permanent magnet poles which provides magnetic field. BLDC Motors have high efficiency, high power to torque ratio, low noise and better operating performances. Supply for BLDC motor is fed with converter. BLDC motor stator voltage and currents are control by the converter. Losses are less and has a long life time because of the BLDC motor does not have brushes and commutator. Due to the electronically Commutation in BLDC motor, the effective speed control is possible and it makes the BLDC is more superior in performance compared to DC brush motors and AC motors. 3 phase bridge converters [2] are used to the control in supply voltage of the BLDC motors, Stator windings of two phases are provided supply and the third phase is isolated. The position of the rotor is decided by the two phases which are having supply. By knowing the rotor position, converter switching devices is turned on. Each switching device is turned on for every 60 degrees. Electronic commutation is happening with this process. So the Back-emf is induced in the stator. BLDC motors have better regulation because of their linear speed and torque characteristics compared to induction motors. So BLDC motors are more suitable for variable frequency drives, electrical vehicle and actuators for industrial robots etc applications.

In robot arm control, electric hybrid vehicles BLDC motors are used. Because of non linear switching control of converter contains the harmonics and its cause to have torque ripple [3].The major disadvantages is torque ripple with that performance of applications are reduced. By using with hysteresis current control [1], non-ideal Back emf sensing [8], magnet segmentation, stator and rotor shape designs of Interior Permanent Magnetic. These methods are used to reduce the torque ripple content for the BLDC motor drive. These methods are best suitable for variable frequency drives (VFD).By the modulation technique Pulses are produced This will reduce the magnitude of harmonics and make the output waveform into a pure sinusoidal. The PWM \&SVPWM [5] methods are used for reducing total harmonic distortion. With the help of PI controller speed of the motor can be controlled, but the selection of proportional gain $\left(\mathrm{k}_{\mathrm{p}}\right)$ and integral gain $\left(\mathrm{k}_{\mathrm{I}}\right)$ is difficult. Some of the nonlinear applications controlling is not possible. So the fuzzy controller [4] was introduced, with the help of this we can easily control the nonlinear applications also. The PMSM with PI and fuzzy controllers [7]-[9] are discussed. With the Fuzzy controller the torque ripple in PMSM with vector control is reduced. To increase the motor stability and to reduce the noise, the fuzzy controller is preferred.

This paper presents the Matlab/simulation of SPWM \& SVPWM with fuzzy control models. The torque ripple analysis is made on these methods. These methods are discussed in this paper to reduce the torque ripple and total harmonic distortion in the output. The motor with the space vector Pulse width modulation compared to Sinusoidal pulse width modulation with fuzzy controller is presented. The speed control scheme of BLDC motor with PWM technique with fuzzy controller is shown in fig.1. 


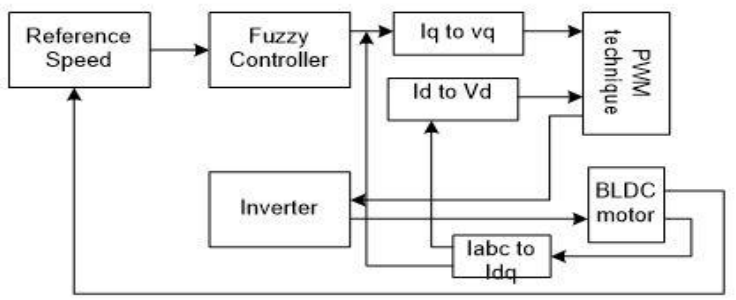

Fig.1: Speed control system of BLDC motor with PWM

\section{Mathematical modeling of BLDC motor}

BLDC with a 3 phase star (Y) connected winding of displaced by $120^{\circ}$ electrical are widely using. BLDCM have a permanent magnet rotor and back emf is induced in the stator winding. The stator winding self-inductance and mutual inductances are constant and equal per phase. Inductance in the motor does not allow sudden change in the current. Voltage is also reduced because of the winding resistance. Stator magnetic field and rotor magnetic field are perpendicular to each other therefore torque is produced with fields interaction. Stator windings cut the flux of rotating rotor; in the stator windings back emf is produced. The stator Electrical equivalent circuit of BLDC motor is shown in fig. 2 .

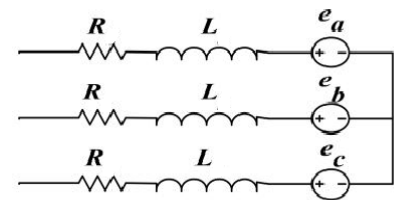

Fig.2: Statorelectrical equivalent circuit of BLDC motor

To control the motor speed and the frequency of the supplied voltage inverter is used.Because of its easy implementationThe most used modulation techniques are SPWM and SVPWM.

$$
\begin{aligned}
& {\left[\begin{array}{c}
\mathrm{V}_{\mathrm{a}} \\
\mathrm{V}_{\mathrm{b}} \\
\mathrm{V}_{\mathrm{c}}
\end{array}\right]=\left[\begin{array}{ccc}
\mathrm{R} & 0 & 0 \\
0 & \mathrm{R} & \mathrm{O} \\
\mathrm{O} & \mathrm{O} & \mathrm{R}
\end{array}\right]\left[\begin{array}{c}
i_{a} \\
i_{b} \\
i_{c}
\end{array}\right]+\left[\begin{array}{ccc}
\mathrm{L}-\mathrm{M} & 0 & 0 \\
0 & \mathrm{~L}-\mathrm{M} & 0 \\
0 & 0 & \mathrm{~L}-\mathrm{M}
\end{array}\right]} \\
& \frac{d}{d t}\left[\begin{array}{l}
i_{a} \\
i_{b} \\
i_{c}
\end{array}\right]+\left[\begin{array}{c}
e_{a} \\
e_{b} \\
e_{c}
\end{array}\right]
\end{aligned}
$$$$
\mathrm{E}_{\mathrm{a}}=\mathrm{k}_{\mathrm{b}} \times \mathrm{f}_{\mathrm{a}}(\theta) \times \omega_{\mathrm{m}}
$$

$\mathrm{E}_{\mathrm{b}}=\mathrm{k}_{\mathrm{b}} \times \mathrm{f}_{\mathrm{b}}\left(\theta-120^{\circ}\right) \times \omega_{\mathrm{m}}$

$$
\mathrm{E}_{\mathrm{c}}=\mathrm{k}_{\mathrm{b}} \times \mathrm{f}_{\mathrm{c}}\left(\theta+120^{0}\right) \times \omega_{\mathrm{m}}
$$

$$
\mathrm{F}=\left\{\begin{array}{cc}
1 & 0 \leq \theta_{\theta} \leq \frac{2 \pi}{3} \\
1-\frac{2 \pi}{3}\left(\theta_{\theta}-\frac{2 \pi}{3}\right) \frac{6}{\pi} \frac{2 \pi}{3} \leq \theta_{\theta} \leq \pi \\
-1 & \pi \leq \theta_{\theta} \leq \frac{5 \pi}{3} \\
-1+\frac{5 \pi}{3}\left(\theta_{\theta}-\frac{5 \pi}{3}\right) & \frac{6}{\pi} \frac{5 \pi}{3} \leq \theta_{\theta} \leq 2 \pi
\end{array}\right.
$$

$T_{e}=\frac{4 * P * N * \phi_{m}^{*} I_{d}}{\Pi * n}$
$\mathrm{T}_{\mathrm{e}}=\mathrm{J} \frac{\mathrm{d} \omega_{\mathrm{m}}}{\mathrm{dt}}+\mathrm{B}_{\mathrm{m}} * \omega_{\mathrm{m}}+\mathrm{T}_{\mathrm{L}}$

Where $T_{L}$ is the load torque, $\mathrm{J}$ is the rotational inertia of the rotor and load, $\mathrm{B}_{\mathrm{m}}$ is the viscous damping coefficient.

$i_{a}=\frac{\int\left(V_{a}-e_{a}-i_{a}^{*} R\right)}{(L-M)} d t \quad i_{b}=\int \frac{V_{b}-e_{b}-i_{b} * R}{(L-M)} d t$

$i_{c}=\int \frac{V_{c}-e_{c}-i_{c} * R}{(L-M)} d t \cdot \omega_{m}=\int \frac{\left(T_{e}-T_{L}-B_{m} * \omega_{m}\right)}{j} d t$

$\theta_{e}=\frac{P}{2} \cdot \theta_{m}, \frac{d \theta_{m}}{d t}=\omega_{m}, \theta_{e}=\frac{P}{2} * \int \omega_{m} d t$

Where,

$\mathrm{F}=$ trapezoidal function of back emf (per phase)

$\theta_{\mathrm{e}}=$ rotor electrical angle

$\mathrm{k}_{\mathrm{b}}=$ motor constant

$\omega_{\mathrm{m}}=$ motor speed

$\mathrm{P}=$ number of poles

$\theta_{\mathrm{e}}=$ electrical angle

$\mathrm{V}_{\mathrm{a}}, \mathrm{V}_{\mathrm{b}}$ and $\mathrm{V}_{\mathrm{c}}$ are the stator phase voltages $. \mathrm{i}_{\mathrm{a}}, \mathrm{i}_{\mathrm{b}}$ and $\mathrm{i}_{\mathrm{c}}$ are the stator phase currents, $\mathrm{L}$ is the self-inductance, $\mathrm{M}$ is the mutual inductance, $\mathrm{R}$ is the resistance of the stator, $\mathrm{T}_{\mathrm{e}}$ is electromagnetic torque, $T_{e}$ is load torque and $B_{m}$ is the damping coefficient.

\subsection{SPWM modulating technique}

It is very easy and common used modulate technique, which is a comparison of three phase sinusoidal signals with the carrier signal at higher frequency, results in the pulses those can be given to the gate signals to the inverter. Then inverter switches are controlled by comparison of carrier and reference signals. The normalized phase voltage (modulation index) is 0.5 . The pulse generation is shown in fig.3.

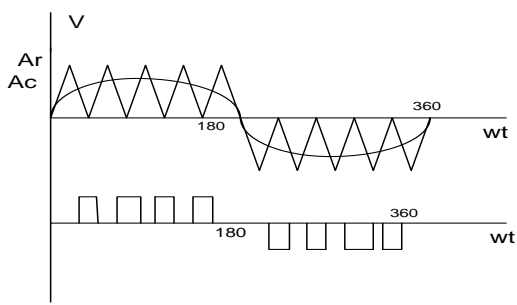

g.3: pulse generation by SPWM

Fi

In the SPWM technique has the triangular frequency (repeating sequence) is the frequency of PWM technique. Converter frequency is controlled by the control voltage frequency. The amplitude is controlled by the maximum value of control voltage. The Modulation Index is given by

$$
M=\frac{V_{C}}{V_{\text {triangular }}}
$$

Where, $\mathrm{Vro}_{1}=$ Fundamental component of supply phase voltage .

If $\mathrm{V}_{\mathrm{c}}>\mathrm{V}_{\text {triangular }}$ then $\mathrm{Vro}=\mathrm{V}_{\mathrm{d}} / 2 \&$ If $\mathrm{V}_{\mathrm{c}}<\mathrm{V}_{\text {triangular }}$ then Vro $=-$ $\mathrm{V}_{\mathrm{d}} / 2$.

\subsection{SVPWM modulating technique}

The basic SVPWM principle is getting the $\mathrm{d}-\mathrm{q}$ axis voltages from the three phase stator voltages. Calculations and pulse generation are made easy with SVPWM than other PWM techniques. Space 
Vector Modulation (SVM) generates the pulses of input supply to the three-level bridge VSI. The three line voltages $\mathrm{V}_{\mathrm{ab}}, \mathrm{V}_{\mathrm{bc}}$ and $\mathrm{V}_{\mathrm{ca}}$ are displaced by $120^{\circ}$ in space. The representation of the three phase voltages as vectors in a two dimensional plane. The sequence of switching has an eight possible states. Every switching state is represented depends upon the leg connection of each phase, here ' 1 ' indicates that phase leg is connected to the positive plate of the DC link, and ' 0 ' indicates that phase leg is connected to the negative plate of the DC link. The' 100 ' switching combination represents that the phase-A output terminal $\mathrm{V}_{\mathrm{a}}$ is connected to the positive DC plate, and phase $\mathrm{B}$ and $\mathrm{C}$ output terminals $\mathrm{V}_{\mathrm{b}}$ and $\mathrm{V}_{\mathrm{c}}$ are connected to the negative DC plate. The effective voltage vector generated by this topology is represented as $V_{1}$. The Representation $\alpha, \beta$ plane switching combination 100 is shown in fig.4.

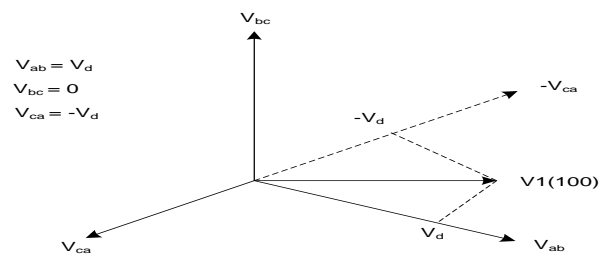

Fig.4: Representation of $\alpha, \beta$ plane switching combination 100 .

Similarly the other switching sequences should be represented by the vector diagram like the above. SPWM has comparing three input waveforms with the high frequency triangular waveform where as SVPWM three inputs are taken simultaneously into a two dimensional frame (d-q axis) and a single quantity representation of a resultant vector. Total switching states with SVPWM are shown in fig.5.

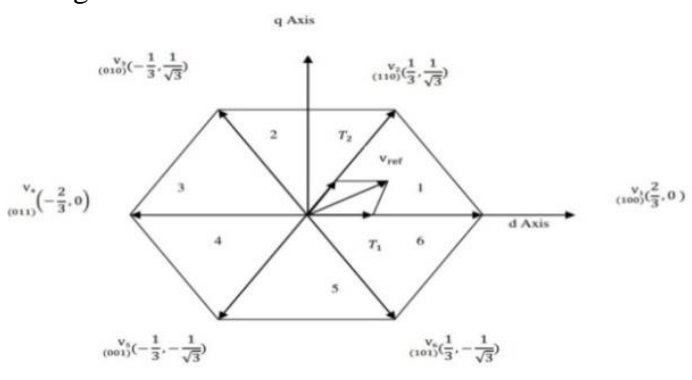

Fig.5: Vector representation of six states with SVPWM

The sector 1 represents the reference voltage.

$\mathrm{V}_{\text {ref }}$ can be represented as

$V_{\text {ref }}=\sqrt{\frac{3}{2}} V_{m} e^{j \theta}$, Where, $\theta=\omega t=2 \pi f t$

$\overrightarrow{V_{\text {ref }}} T_{\Omega}=\overrightarrow{V_{1}} T_{1}+\overrightarrow{V_{2}} T_{2}$

Where, $T_{s}=\frac{1}{f_{s}}, f_{s}=$ switching frequency,

$\emptyset=\theta-(N-1) 60^{\circ}$

$\emptyset$ is an angle within 0 to 60 degrees for each vector.

The switching periods are determined by below equations,

$T_{1}=T_{a} \frac{2}{\sqrt{3}} \frac{V_{\text {ref }}}{V_{1}} \sin \left(60^{\circ}-\emptyset\right)$

$T_{2}=T_{s} \frac{2}{\sqrt{a}} \frac{V_{\text {ref }}}{V_{2}} \sin (\phi)$,

$T_{0}=T_{s}-\left(T_{1}+T_{2}\right)$
Lower order harmonics are reduced and high modulation index with SVPWM. It provides the high Output fundamental voltage, Reduce the harmonic content and less THD.

\subsection{Simulation model of BLDCM with Fuzzy controller}

Fuzzy controller is a linguistic controller based on fuzzy logic. For fuzzy controller two inputs those are, error and change in error of a speed is required. The fuzzy controller output is the current. Conditions and rules are present between the output and input data The membership functions for speed error, change in speed error and current shown in the below figures.

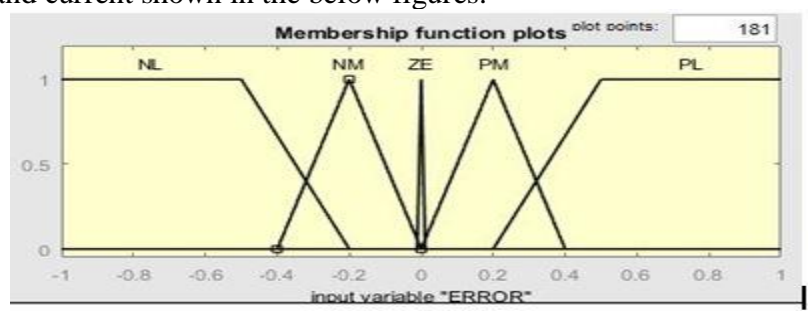

Fig.3. Membership values of the error signal

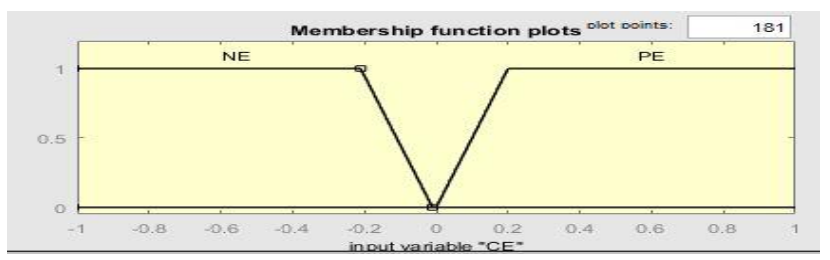

Fig.4. Membership values of the change in error signal

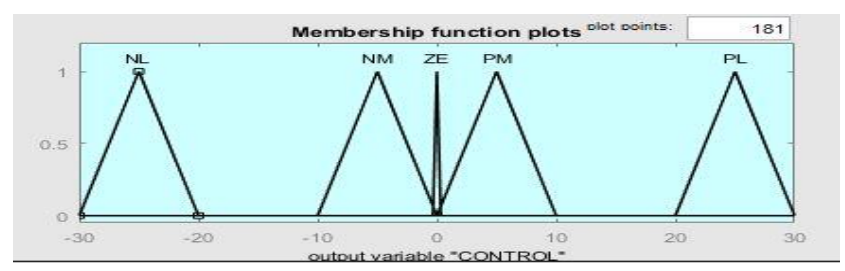

Fig.5. Membership values of the control signal

The fuzzy inference rules are shown in below table. The seven rules are the conditions to decide the output depends on input. The rules are,

1. If error $=\mathrm{PL}$ then control $=\mathrm{PL}, 2$. If error $=\mathrm{NL}$ then control $=$ $N L$, 3. If error $=Z E$ and change in error $=N E$ then control $=N M$, 4. If error $=\mathrm{ZE}$ and change in error $=\mathrm{PE}$ then control $=\mathrm{PM}$, 5. If error $=\mathrm{NM}$ then control $=\mathrm{NM}, 6$. If error $=\mathrm{PM}$ then control $=$ PM

and7. If error $=\mathrm{ZE}$ then control $=\mathrm{ZE}$.

Example: from $5^{\text {th }}$ rule error in speed (Per unit) is between -0.4 to 0 then control (Iq) is between -10 to 0 amps.

\subsection{Specifications of motor}

\begin{tabular}{|c|c|}
\hline Parameter & Rating \\
\hline Input DC voltage & $150 \mathrm{~V}$ \\
\hline Resistance of stator & 0.2 \\
\hline Inductance of stator & 0.0030 \\
\hline Load torque & $5 \mathrm{Nm}$ \\
\hline Torque constant & $0.49 \mathrm{Nm} / \mathrm{A}$ \\
\hline Moment of inertia & 0.0005 \\
\hline Number of Poles & 4 \\
\hline
\end{tabular}




\section{Simulation models}

The simulation model of BLDC motor with the SPWM and SPWM are shown in below in fig 6 and fig 7 .

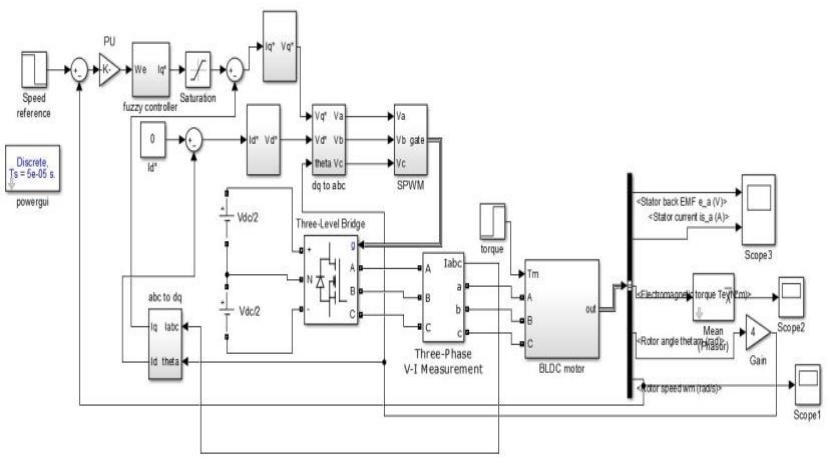

Fig: 6 simulation of BLDC motor with SPWM technique

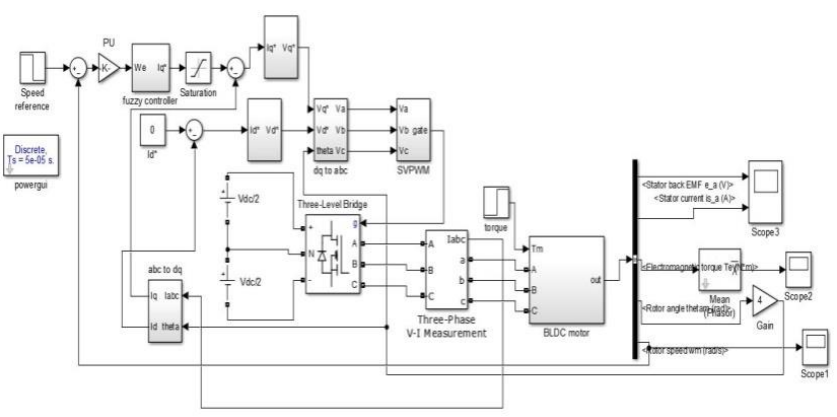

Fig: 7 Simulation of BLDC motor with SVPWM technique

\subsection{Simulation Results}

The back emf and stator current simulation results of BLDC motor with the SPWM are shown in fig 8.
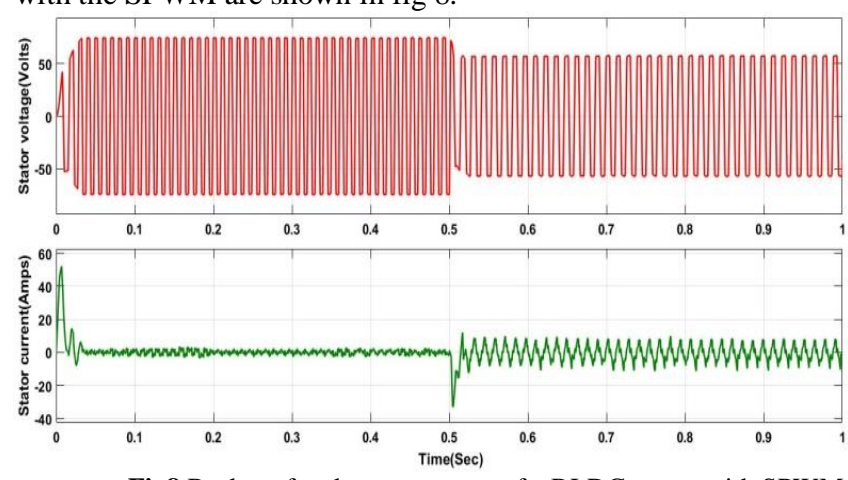

Fig8.Back emf and stator current of a BLDC motor with SPWM.

The back emf and stator voltage simulation results of BLDC motor with the SVPWM are shown in fig 9.
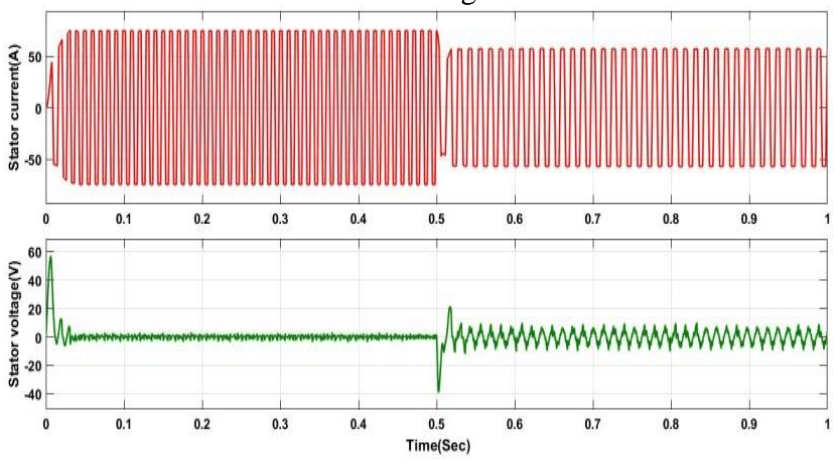

Fig 9.Back emf and stator current of a BLDC motor with SVPWM

The stator line voltage simulation results of BLDC motor with SPWM are as shown in fig 10 .

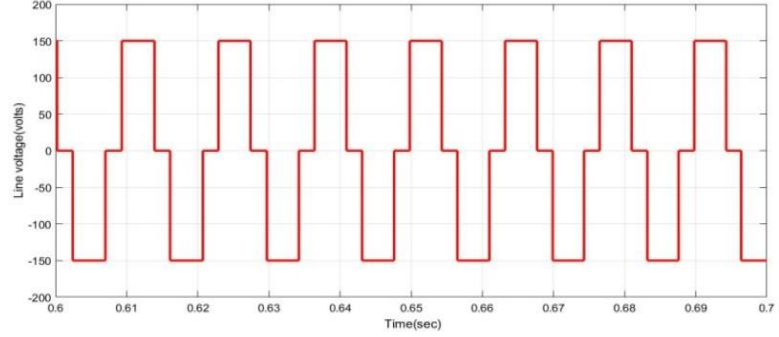

Fig10. The stator line voltage simulation results of BLDC motor withSPWM

The stator line voltage simulation results of BLDC motor with SVPWM are as shown in fig 11.

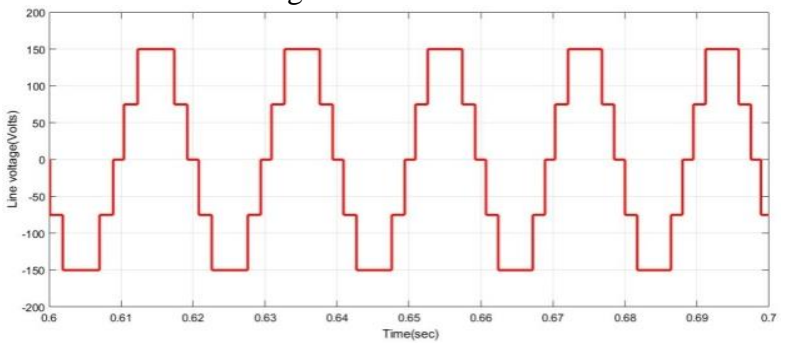

Fig11. The stator line voltage simulation results of BLDC motor with SVPWM

From the Fig10\& Fig11 with SVPWM method. The produced stator line voltageshave less harmonics compared to the SPWM method. The stator line voltage is approaching to sinusoidal in SVPWM.

The speed curve of simulation results of BLDC motor with the SPWM is as shown in fig 12.

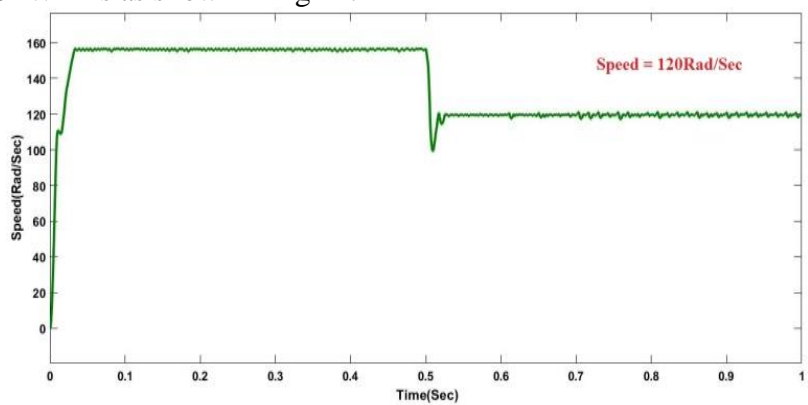

Fig12. The speed curve of BLDC motor with the SPWM

From the Fig12, the mechanical load of $5 \mathrm{Nm}$ is applied at $0.5 \mathrm{Sec}$ then the rotor speed falls down and tracking along with the reference speed.In the speed curve, there existing some oscillations in speed.

The speed curve of simulation results of BLDC motor with the SVPWM is as shown in fig 13.

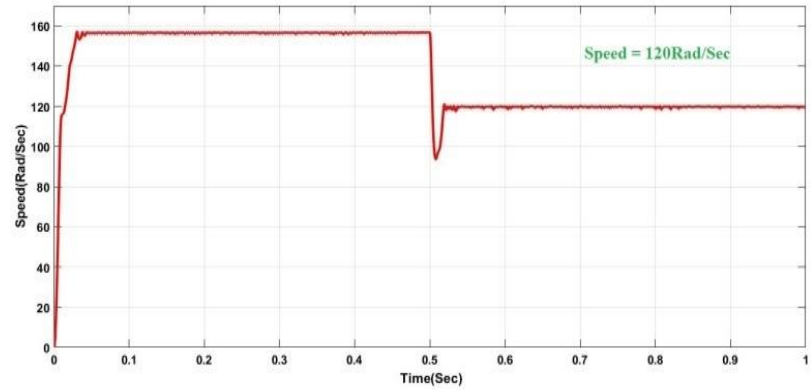

Fig13. The speed curve of BLDC motor with the SVPWM

From the Fig 14, the mechanical load of $5 \mathrm{Nm}$ is applied at $0.5 \mathrm{sec}$, the dip in the rotor speed is less in case of SVPWM method compared to SPWM method \& speed oscillations are less in SVPWM. The rotor speed is tracking according to the reference speed.

The torque wave form of simulation results of BLDC motor with the SPWM is as shown in fig 14. 


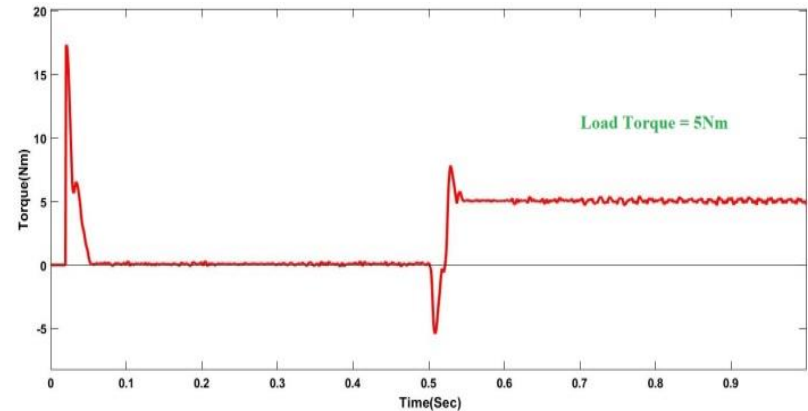

Fig.14.Torque curve of a BLDC motor with SPWM.

The torque wave form of simulation results of BLDC motor with the SVPWM is as shown in fig 15.

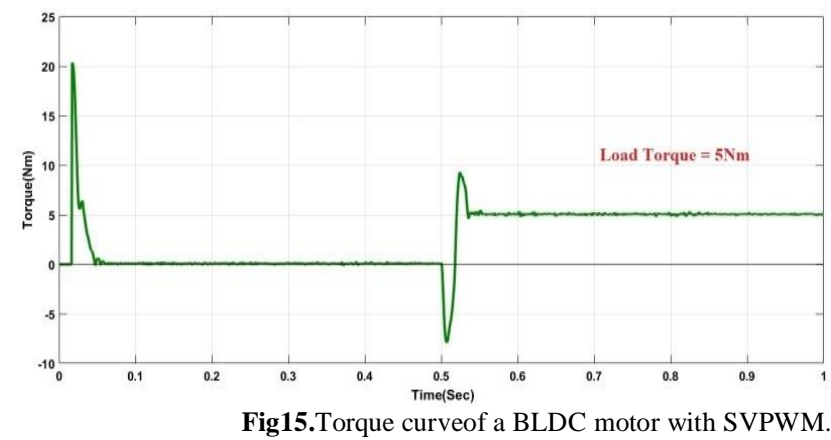

The simulation result of the torque curve at steady state is as shown in fig 16.

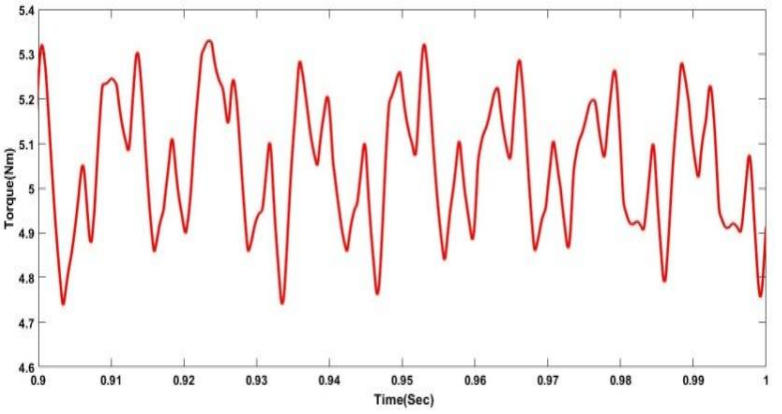

Fig16. Torque curve at steady state with SPWM

The simulation result of the torque curve at steady state is as shown in fig 17.

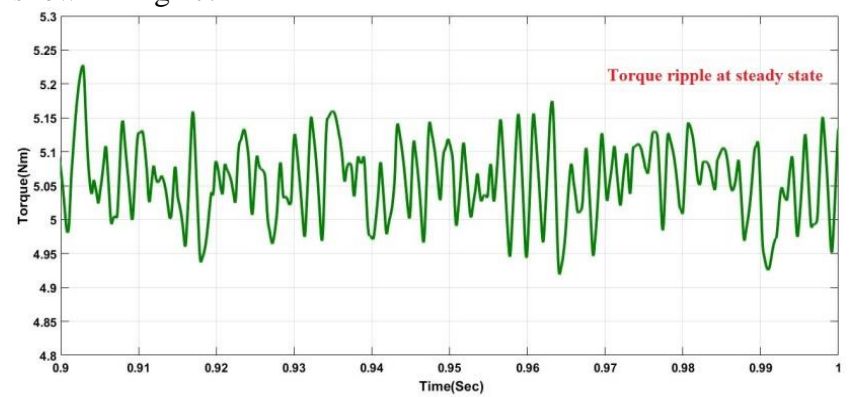

Fig 17. Torque Curve at steady state with SVPWM

\subsection{Torque Ripple calculation:}

The ratio of peak to peak value to the average value of torque is defined as the Torque ripple.

$$
\mathrm{T}_{\text {ripple }}=\frac{\mathrm{T}_{\max }-\mathrm{T}_{\min }}{\mathrm{T}_{\text {avg }}}
$$

From the fig17, Torque ripple $=(5.3-4.75) / 5=0.11$

$\%$ torque ripple $=11 \%$

From the fig18, Torque ripple $=(5.17-4.93) / 5=0.048$
$\%$ torque ripple $=4.8 \%$

1. Torque ripple comparison table

\begin{tabular}{|c|c|c|}
\hline S.No & Method & \% Torque ripple \\
\hline 1. & Sinusoidal PWM & $11 \%$ \\
\hline 2. & Space vector PWM & $4.8 \%$ \\
\hline
\end{tabular}

\section{Conclusion}

The performances of BLDC motor areobserved by Matlab/ simulation. With the help of modulation techniques, the torque ripple reduces to some extent. By using the PWM method, the percentage of torque ripple is reduced to $11 \%$. With the proposed SVPWM, the torque ripple still reduced to $4.8 \%$. The SVPWM is taking less current during speed control and the utilization of DC supply effectively over SPWM method. The speed curve is taking less time to settle and haslow oscillations in SVPWM. This result SVPWM is the best suited method to control the converter supply to the BLDC motor.

\section{References}

[1] Naim suleyman, Yusuf yasa, Ismail aksoy,Yakup sahin. "Comparison of SVPWM, SPWM and HCC Control techniques in Power Control of PMSG used in wind Turbine Systems". 978-1-47637239-8/15. 2015 IEEE.

[2] B. K. Swamy, P. N. Rao, "Simulation of A Space Vector PWM Controller for A Three-Level VoltageFed Inverter Motor Drive",International Journal of Advanced Trend in Computer Science andEngineering, 2013, pp. 363-372.

[3] Viswanathan V. Jeevananthan S."Approach for torque ripple reduction for brushless DC motor based on three-level neutral-point-clamped inverter with DC-DC converter", IET Power electron., 2015, 8, (1), pp. 47-55.

[4] Tridibesh Nag, SubhenduBikashSantra, ArunavaChatterjee, DebashisChatterjee, "Fuzzy logic-based loss minimisation scheme for brushless DC motor drive system", IET Power electronics,IET Power Electron, 2016, Vol. 9, Iss. 8, pp. 15811589.

[5] K.V. Kumar, P.A. Michael, J.P. John, S.S. Kumar, "Simulation andComparison of SPWM and SVPWM Control for Three Phase Inverter", ARPN Journal of Engineering and Applied Sciences, pp. 63-74, 2010.

[6] AtifIqba, AdoumLamine, I. Ashra and Mohibullah, "Matlab/Simulink Modelof Space Vector PWM for Three-Phase Voltage Source Inverter". Universities Power Engineering Conference, 2006.

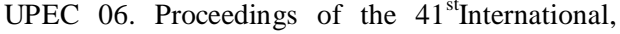
Vol. 3.

Ahmed m. Ahmad, Amir ali-eldin, Mohamed s.elksasy, Fiazf.areed, "brushless de motor speed control using both pi controller and fuzzy controller",international journal of computer applications"(0975-8887)volume 109-no.10, january 2015.

A. Nair, K. R.Rajagopal, "A novel back-EMF detection scheme based sensorless control of permanent magnet brushless DC motor drive," in Proc. Int. Conf. Elect. Mach. Syst., 2010, pp. 978-983.

[9] GuesmiOussama, Mr. alidoulik. "Comparison between PI and Fuzzy controllers in speed control of PMSM".978-1-5090-6287-

4/17/\$31.00,2017,IEEE. 